\title{
Reasonable Utilization of Fishing Berth based on Arena
}

\author{
Gui Jinsong \\ Dalian Ocean University \\ Dalian, China \\ 31795968@qq.com \\ Wen Zhichao \\ Dalian Ocean University \\ Dalian, China \\ wen012103@163.com
}

\author{
Bi Enkai \\ Dalian Ocean University \\ Dalian, China \\ xiaobienkai@163.com
}

\begin{abstract}
Fishing port planning and construction is very important to the economic development of our country .This article is based on Arena simulation software to calculate the reasonable utilization of fishery discharging port berth, and tests this with the method of queuing theory, which indicates the results of simulation calculation is correct. During this modeling process, related optimization strategy is applied to verify and analyze the model for providing further plan .The article can be quoted for fishing port planning. For complex fishing port operation system, if it is simulated by a computer program .Low efficiency, and error-prone may happen. But Arena simulation software is simple and practical ,it is good to solve the problem. Therefore, the use of this software in the numerical simulation of fishing port, can greatly improve the work efficiency and scientific planning for fishing port and it will play an important guiding role.
\end{abstract}

Keywords-queuing theory; simulation; Arena; berth utilization; fishing port

\section{INTRODUCTION}

Arena simulation software is developed by Rock Well company in 1993. The waiting fee for fishery vessels mainly includes economic losses caused by the vessels that unable to fish in time. So the ship parts hope fishing port has a sufficient number of berth. While terminal parts hope to have a higher berth utilization to lower their fees. The idle fee of port berth mainly has port hydraulic structures in average cost [1]. The optimal number of berths fishing port should reduce the comprehensive cost of ship and terminal parts to the minimum. The corresponding berth utilization is optimal.

\section{ARENA SIMULATION MODEL}

Arena represents a new level of modern computer simulation. Arena is process oriented software, the socalled process oriented, is build a process for all entities, entities from rise to fall all activities, but also to provide users with simulation event tracking function. Practice research proves that, as a general visual interactive integrated simulation environment, the application range of the Arena is very broad, covering almost all areas of the visual simulation, including the manufacturing system, public system and service system. Especially in the service system has a very wide range of applications, such as: the transportation of the highway traffic control, the management of the taxi and route control, the container terminal logistics system simulation and optimization research, port transportation planning model, vehicle scheduling, etc.

\section{A. Effect}

Fish fishing port of discharging terminal computer simulation is used in the process of simulation production module. According to the random arrival time interval for fishing vessels and ship type of probability distribution, a series of coming vessels is made to simulate the production process, gradually accumulated on sample statistics, until the expiry of the simulation, so as to make a simulation test on fishing port production process.

\section{B. Law of ships to arrive}

By the distribution laws of random daily number to port ship statistical analysis shows that the daily number of arriving boats obey the Poisson Distribution. The time interval of fishing boats to reach with the same parameters take lambda from negative exponential distribution, which have reached the time interval of two fishing boats for a certain number of $t$ is probability density.

$$
\begin{aligned}
& g t=\lambda e^{-\lambda t} \\
& \lambda=N / 365
\end{aligned}
$$

\section{( $N$ stands for total number of voyage)}

\section{Time in loading fish pier for boats}

The time for boats to occupy berths is the sum of in and out of ports and discharging time, when a large number of customer service time is short, and a small amount of the customer needs a much longer service time, service time obey negative exponential distribution. There 
is data show that taking time for merchant basically obey negative exponential distribution [2], if service time obeys negative exponential distribution, computational formula is sufficient and easy to use.

\section{Simulation Process}

- Generated ships: fishing vessels are produced by the Create module, and then assign volume .ship sizes.etc valve to the boats in the Assign module.

- Service unloading fish: According to the difference of different amount, ship size fish is processed after the arrival of fishing boats.

- $\quad$ The ship left port: ships leave fishing port after service. man force efficiency : $2 \mathrm{t} / \mathrm{h}$, marine crane: $5 \mathrm{t} / \mathrm{h}$, shore unload fish machines: $15 \mathrm{t} / \mathrm{h}$. $\mathrm{t}$ stands for in, out of berth time and preparing time, 1 hour. Negative exponential distribution parameter $\mathrm{Tb}=\mathrm{t}+5 / \mathrm{P}_{1}\left(\mathrm{P}_{1}\right.$ is unloading fish mechanical effective discharge capacity. Units: tons/ hours)

\section{THE OPTIMAL BERTH UTILIZATION}

The utilization is optimal for port ships when comprehensive cost of the two sides is lowest. In order to make the calculation results comparable, according to the unit of fishing cargo cost comparison ,i.e. the total cost, how much is that when every tons of fish is processed. The representative ship size is $147 \mathrm{kw}(200 \mathrm{HP})$, volume is 5 tons. Fishing vessels to berth fee to consider the loss caused by fishing vessels to berth delay catching season and fishing boats berth leisure expenses such as depreciation cost, maintenance of breakwater berth total construction fee to gauge are taken into account, the cost of the channel, maintenance and operating costs. Through the investigation of the fishing port[5], collected a large amount of information about the terminal, the ship cost, through comprehensive analysis, the cost of fishing vessels to berth Cs and garages free charge between the ratio of the $\mathrm{Cb}$ for 3 to 5 . This paper uses value of 4 .

\section{Queuing TheORETIC Models}

For fishing port a stochastic service system, fishing boats can be seen as a customer, the $\mathrm{M} / \mathrm{M} / \mathrm{K}$ model, queuing rules is adopted by first come first service rules [3].

\section{A. The main calculation formula}

- $\quad$ Berth utilization

$$
\rho=\frac{\lambda}{\mu \mathrm{k}} \quad \lambda=N /(24 \times 365)
$$

- $\quad$ Probability of all berths are idle $P_{0}$

$$
P_{0}=\left[\sum_{N=0}^{k-1} \frac{\rho^{\prime n}}{n !}+\frac{\rho^{\prime k}}{k !} \frac{k}{k-\rho^{\prime}}\right]^{-1} \quad \rho^{\prime}=\lambda / \mu
$$

- Expectations of fishing boat waiting to unload fish ship number

$$
E[L]=\frac{\rho^{\prime k}}{n !} \frac{\rho^{\prime} k}{\left(k-\rho^{\prime}\right)^{2}} p_{0}
$$

- $\quad$ Expectations of fishing boat waiting time E[W]

$$
E[W]=\frac{E[L]}{\lambda}
$$

- $\quad$ Total time of yearly queuing boats

$$
M_{s}=N \cdot E[W]
$$

- $\quad$ Total time of yearly idle berths

$$
\mathrm{M}_{\mathrm{b}}=365 \bullet \mathrm{k}\left(1-\frac{\lambda}{\mathrm{k} \mu}\right)
$$

\section{THE COMPARISON BETWEEN SIMULATION RESULTS AND QUEUING THEORY}

When fishing port berths are for sure, put the number of boats from less to more, if the fish quantity cost minimum, the berth utilization is optimal at the moment.

\section{A. Figures and Tables}

- TABLE 1: Reasonable berth utilization results summary

- FIGURE 1: Reasonable berth utilization calculation

- TABLE 2: Specified fish quantity cost summary

- FIGURE 2: Process

\section{ARENA SIMULATION ADVANTAGE}

Rational use of queuing theory method to calculate the berth utilization, some limitations, need to select representative form, the large deviation with the actual situation. For a simple fishing port out, such as fish, fishing boats leave port and dock, discharge process, using queuing theory method to calculate fair. But if port to form more, take berth time is different, after unloading fish, fishing boats are not directly from other ports, you also need to add ice, gas, water and other operations, and is likely to have generated new queue again, in the process of the system constitutes a new influence, for such a complex, to simulate the operation process need to write a lot of programs, error-prone [4]. At the same time, the system of the large number of random events is also directly affect the service level of the entire system and the running cost, therefore, have done a lot of abstract and simplify the conventional mathematical methods are difficult to deal with such a complex problem. And Arena simulation software with its unique advantage, very good to solve the problems, make the simulation modeling an easy task. Therefore, reasonable use of this software in the fishing 
port simulation, can greatly improve the work efficiency, will play an important role in scientific planning of fishing port.

While using the simulation software, Arena has the following advantages:

a) No need to programming, clear logical relations, simple to understand and operate and not easy to go wrong.

b) Break through the bondage of traditional queuing theory make logical relationship more close to reality, not to the fishing port to simplify the relevant indicators, the average processing.

c) Arena results can be used to get more about the numerical simulation results, in this paper, for example, in addition to get the berth utilization, unit cost, also can get (take berth number 1, number of fishing boats, 800, for example),run for 50 times.

- The average berthing time of unload fish: $3.42 \mathrm{~h}$; Maximum (minimum) average: $3.58(3.22) \mathrm{h}$

- $\quad$ The average waiting time: $1.59 \mathrm{~h}$;

The max (min) waiting time : 2.25 (1.26) $\mathrm{h}$

- Fishing port stay: $5 \mathrm{~h}$;

- $\quad$ Average maximum stay (minimum) : 5.66 (4.79) h

- The average number of discharging boats in port : 0.46 ;

- Largest number of the ship in the port of discharging: 9

- Average number of boats waiting for unloading: 0.1462 ; The largest average ( $\mathrm{min}): 0.21(0.21)$

- $\quad$ Largest( $\mathrm{min})$ berth utilization: 0.332 (0.287).

\section{THE RESULTS OF SIMULATION ANALYSIS}

- From table 1, 2, Chart 1 shows, Arena simulation results and the queuing theory calculation results are consistent, Arena simulation result is correct.

- The increased number of berths, berth utilization rate.

- The unloading fish had a little effects on reasonable berth utilization efficiency.

- The unit cost decreases with increasing amount of fish.

\section{REMAINING QUESTIONS}

To a pre-determined amount of fish to the port number of fishing boats or years under the condition of simulation, we need early adjustment Create module parameter values, the parameters of the poisson distribution, make the simulation results from the number and the conditions for fishing boats in the harbor is consistent, the process must be repeated debugging, to draw a unit cost a minimum amount of fish in the optimal berth utilization.

\section{ACKNOWLEDGMENT}

The essay is made under my and my tutor's common efforts. Thanks to my tutor Professor Gui. Without his help, I couldn't have finished this essay so quickly. During this process ,I have learned so much from him. His rigorous attitude spurs me to modify it over and over again

\section{REFERENCES}

[1] Gui JinSong, “The discussion about distribution of coming boats to the port at random, "on Journal of Dalian Fisheries Universit y. Vol. 14, No. 3, Sep . 199 9,pp.67-70.

[2] Gui JinSong, Li Shengde, "Research on reasonable berth utilization of fish discharging ports,"on Ocean Engineering. Vol. 18 ,No . 3, Aug . 2000,pp.51-56.

[3] Gui JinSong. "Definition on ratio of stay fare and idle berths cost."on Water Transport Engineering, Vol .7, 1999,pp.47-51.

[4] Gui JinSong,Li Shengde, “ Using queuing theory method to determine fish fishing port discharge port optimal berth utilization,"onJournalDalianUniversity,Vol,6.No.23,Dec.1999. pp.49-52.

[5] Liu Fengshan. Queuing theory and its application [M]. Hubei science and technology press, 1984.

[6] He Xuansen, "Random Process and Queuing Theory."Hu Bei University Press,pp.178-225.

[7] Kelton. "Simulation of Arena Software." Mechanical Industry Press.pp.23-276.

[8] Ni Xiaoyang. "Simulation based on the Queuing Theory of Container Terminal Berth and Shore Bridge Joint Configuration" Tian Jin University.pp.9-28.

[9] Yu Chuntian,Li Fachao. "Operational Research" Science Press,pp.147-203.

[10] Mark,B,D,Joseph,J,M,E,Jaap,A,O. “A simulation model for integrating quay transport and slacking policies on automated container terminals Proceedings of the 15th European Simulation Multicongruence" 2001. 6 .

[11] Lai, K K, Leung J. Analysis of gate house operations in a container terminal. International Journal of Modelling and Simulation, 2000, 20(1): 89-94. 
TABLE I. REASONABLE BERTH UTILIZATION RESULTS SUMMARY

\begin{tabular}{|c|c|c|c|c|c|c|c|c|c|}
\hline \multirow{2}{*}{ Berth } & \multicolumn{3}{|c|}{ Efficiency 2t/h } & \multicolumn{3}{c|}{ Efficiency 5t/h } & \multicolumn{3}{c|}{ Efficiency 15t/h } \\
\cline { 2 - 10 } & boat & $\begin{array}{c}\text { Arena } \\
\text { result }\end{array}$ & $\begin{array}{c}\text { Queue } \\
\text { result }\end{array}$ & boat & $\begin{array}{c}\text { Arena } \\
\text { result }\end{array}$ & $\begin{array}{c}\text { Queue } \\
\text { result }\end{array}$ & boat & $\begin{array}{c}\text { Arena } \\
\text { result }\end{array}$ & $\begin{array}{c}\text { Queue } \\
\text { result }\end{array}$ \\
\hline 1 & 800 & 0.320 & 0.312 & 1400 & 0.320 & 0.313 & 2200 & 0.335 & 0.328 \\
\hline 2 & 2200 & 0.439 & 0.418 & 3800 & 0.434 & 0.422 & 5600 & 0.426 & 0.429 \\
\hline 3 & 3800 & 0.506 & 0.500 & 6600 & 0.502 & 0.485 & 9800 & 0.497 & 0.487 \\
\hline 4 & 5400 & 0.539 & 0.523 & 9400 & 0.537 & 0.521 & 14200 & 0.540 & 0.538 \\
\hline 5 & 7200 & 0.575 & 0.571 & 12600 & 0.575 & 0.563 & 18800 & 0.572 & 0.560 \\
\hline 6 & 9000 & 0.599 & 0.608 & 15800 & 0.601 & 0.586 & 23600 & 0.599 & 0.586 \\
\hline 7 & 10800 & 0.616 & 0.609 & 19000 & 0.620 & 0.618 & 28600 & 0.622 & 0.637 \\
\hline 8 & 12800 & 0.639 & 0.644 & 22400 & 0.639 & 0.674 & 33600 & 0.639 & 0.629 \\
\hline 9 & 14800 & 0.657 & 0.645 & 25800 & 0.654 & 0.666 & 38600 & 0.653 & 0.642 \\
\hline 10 & 16800 & 0.671 & 0.670 & 29200 & 0.667 & 0.678 & 43800 & 0.681 & 0.679 \\
\hline 11 & 18800 & 0.683 & 0.677 & 32800 & 0.681 & 0.675 & 49200 & 0.681 & 0.683 \\
\hline 12 & 20800 & 0.693 & 0.684 & 36200 & 0.689 & 0.685 & 54400 & 0.690 & 0.686 \\
\hline 13 & 22800 & 0.701 & 0.689 & 39800 & 0.699 & 0.689 & 59800 & 0.700 & 0.698 \\
\hline 14 & 24800 & 0.708 & 0.713 & 43400 & 0.708 & 0.696 & 65200 & 0.709 & 0.712 \\
\hline 15 & 26800 & 0.713 & 0.711 & 47400 & 0.717 & 0.714 & 71300 & 0.719 & 0.718 \\
\hline
\end{tabular}

Figure 1. Reasonable berth utilization calculation

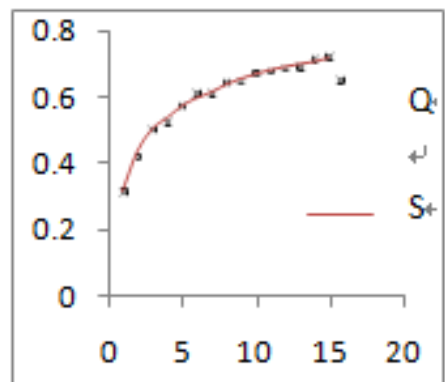

$\mathrm{P}_{1}=2 \mathrm{t} / \mathrm{h}$

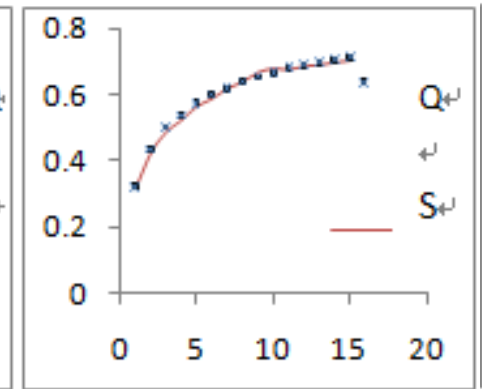

$\mathrm{P}_{1}=5 \mathrm{t} / \mathrm{h}$

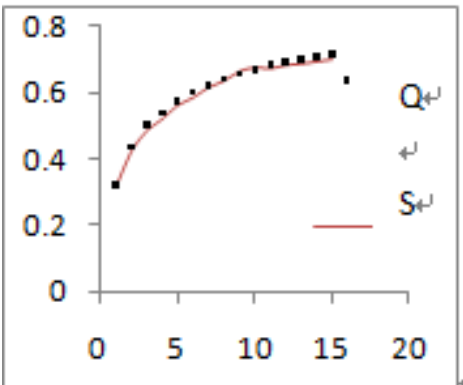

$\mathrm{P}_{1}=15 \mathrm{t} / \mathrm{h}$

Q : Queuing Theory Result $\quad$ S : Simulation Result

Figure 2. Process

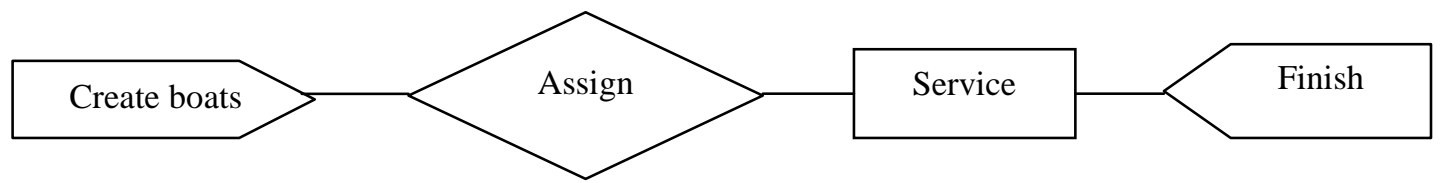




\begin{tabular}{|c|c|c|c|c|c|c|}
\hline \multirow{2}{*}{ Berth } & \multicolumn{2}{|c|}{$\mathrm{P}=2 \mathrm{t} / \mathrm{h}$} & \multicolumn{2}{c|}{$\mathrm{P}=5 \mathrm{t} / \mathrm{h}$} & \multicolumn{2}{c|}{$\mathrm{P}=15 \mathrm{t} / \mathrm{h}$} \\
\cline { 2 - 7 } & Arena & Queue & Arena & Queue & Arena & Queue \\
\hline 1 & 0.121 & 0.116 & 0.065 & 0.066 & 0.045 & 0.044 \\
\hline 2 & 0.067 & 0.065 & 0.037 & 0.037 & 0.024 & 0.025 \\
\hline 3 & 0.045 & 0.047 & 0.028 & 0.027 & 0.018 & 0.018 \\
\hline 4 & 0.034 & 0.038 & 0.023 & 0.022 & 0.014 & 0.015 \\
\hline 5 & 0.033 & 0.033 & 0.018 & 0.019 & 0.013 & 0.012 \\
\hline 6 & 0.031 & 0.029 & 0.016 & 0.016 & 0.012 & 0.011 \\
\hline 7 & 0.027 & 0.026 & 0.015 & 0.015 & 0.011 & 0.01 \\
\hline 8 & 0.025 & 0.024 & 0.013 & 0.014 & 0.01 & 0.009 \\
\hline 9 & 0.023 & 0.022 & 0.013 & 0.013 & 0.009 & 0.008 \\
\hline 10 & 0.021 & 0.02 & 0.011 & 0.012 & 0.008 & 0.008 \\
\hline 11 & 0.019 & 0.019 & 0.011 & 0.011 & 0.008 & 0.007 \\
\hline 12 & 0.019 & 0.018 & 0.01 & 0.01 & 0.007 & 0.007 \\
\hline 13 & 0.018 & 0.017 & 0.009 & 0.01 & 0.006 & 0.007 \\
\hline 14 & 0.017 & 0.017 & 0.009 & 0.009 & 0.005 & 0.006 \\
\hline 15 & 0.017 & 0.016 & 0.009 & 0.009 & 0.005 & 0.006 \\
\hline
\end{tabular}

